\title{
POLICY ARENA
}

\section{AGRICULTURAL MARKET LIBERALIZATION: A CASE STUDY OF THE WESTERN CAPE PROVINCE IN SOUTH AFRICA}

\author{
JOHAN VAN ZYL, NICK VINK, ROB TOWNSEND AND JOHANN KIRSTEN
}

\section{INTRODUCTION}

South African agriculture has a long history of ever increasing governmental intervention, reaching a zenith in approximately 1980, with a horde of laws, ordinances, statutes and regulations. These measures affected all aspects of agriculture, including prices of and/or access to and/or use of natural resources, finance, capital, labour, local markets, foreign markets, foreign exchange, etc. Political and economic power had become highly concentrated (Kassier and Groenewald, 1992). The policy environment of racial discrimination and price distortions, however, could not be sustained. The period since 1980 is characterized by a reversal of past policies, resulting in removal of the racial barriers between black and white agriculture, and increased liberalization and democratization of the agricultural sector.

Agricultural marketing reform is a major source of change in South and Southern African agriculture, as market interventions constituted one of the major instruments of government control (Kirsten and Van Zyl, 1996). The economic effects of these changing policies differ from region to region. This paper attempts to estimate the effects of some of the changes in the marketing system on the Western Cape Province of South Africa, utilizing a regional linear programming model of the agricultural sector of the region.

The paper is organized as follows: the next section provides a brief description of the changing agricultural policy environment in South Africa, followed by the model constructed for the analysis, i.e. modelling of supply, demand and risk in the Western Cape agricultural sector, in Section 3. Section 4 consists of the data requirements, followed by testing of the model for its accuracy and predicting abilities. The model is subsequently used to simulate a number of different policy scenarios. Some recommendations conclude the paper.

\section{THE CHANGING AGRICULTURAL POLICY ENVIRONMENT}

Agricultural policy in South Africa during the 1980s was determined by the 1983 constitutional dispensation, which provided for the continuation of a dualistic agricultural policy and industry. Policy with regard to 'white' commercial agriculture was outlined by 
the White Paper on Agricultural Policy tabled in 1984. One of the major aims of agricultural policy in South Africa during the 1980s was 'self-sufficiency in respect of food, fibre and beverages and the supply of raw materials to local industries at reasonable prices' (RSA, 1984). The White Paper motivates this policy aim as follows: 'For any country, the provision of sufficient food for its people is a vital priority and for this reason it is regarded as one of the primary objectives of agricultural policy. Adequate provision in this basic need of man not only promotes, but is also an essential prerequisite for an acceptable economic, political and social order and for stability.'

One of the major instruments to achieve the goals of the White Paper of 1984 was the Agricultural Marketing Act (Act 59 of 1968 as amended). The Act enables the Minister of Agriculture to proclaim a marketing scheme to control the marketing of a particular commodity. The Act provides for the promulgation of subordinate legislation called schemes. A total of 23 marketing schemes were established under the Marketing Act. With these schemes it was possible to: (i) transform the agricultural output and input marketing system; (ii) determine commodity prices, the level and stability of food prices; and (iii) to create certain concentrations of monopoly power, especially in agricultural processing industries.

Since the mid-1980s, agricultural policy was characterized by increasing deregulation and market liberalization. Vink (1993) argues that the deregulation of the agricultural sector started outside agriculture in the late 1970s when the financial sector was extensively liberalized, leading to the increasing exposure of farmers to market-related interest and exchange rates (World Bank, 1994). Other changes in the broader political economy, which led to changes in agricultural policy, were the lifting of controls over the movement of labour in South Africa in the mid-1980s, and the considerable microeconomic deregulation leading to increased activity in the informal sector.

A number of political-economic pressures have led to a more market-related approach in the marketing of agricultural commodities in South Africa since the early 1980s. There was a reduction in the use of price control on a number of commodities. There were also shifts to more market-based pricing systems, away from the old cost-plus pricing procedure. Other pressures came from within the system, with many farmers becoming increasingly unhappy with aspects of the controlled marketing of many agricultural products. There was also a realization of the poor performance of the agricultural sector in aggregate, as measured by the very slow rate of productivity growth (Thirtle et al, 1993). In addition to the sectoral reforms, the economic environment for agriculture has been profoundly affected by changes to macro-economic policy, most notably the tightening of monetary policy through increases in interest rates and exchange rate depreciation.

The trend of market liberalization was further enhanced by the pressures emerging from the GATT negotiations for the abolishment of quantitative import controls and the introduction of tariffs on all agricultural commodities. The replacement of quantitative controls on external trade by tariffs was intended to: (i) reduce the distortions created by quantitative administrative controls; (ii) create a more commercial environment in the planning of imports; (iii) reduce the role of government in the allocation of licenses; (iv) limit the use of quantitative controls; and (v) increase the extent of competition. A general policy of tariffication has been in operation since 1985, but this has only begun to be applied to agricultural commodities since 1992. During 1994, tariffs were established for poultry, tobacco, vegetable oil, oilcake and red meat, and an overall strategy has been developed for submission to GATT.

The appointment by the Minister of Agriculture of the Committee of Inquiry into the Marketing Act (CIMA) in June 1992, was probably the main event triggering the process of market deregulation since the beginning of 1993. Since the release of the CIMA report in January 1993, the majority of the marketing schemes and marketing boards were 
abolished. This process was largely the result of the adoption of a new Agricultural Marketing Act by the Government of National Unity in 1995.

\section{THE MODEL}

Sectoral and regional mathematical programming models in agriculture have been discussed in some detail by a number of authors, including Hazell and Norton (1986). This section concentrates on utilizing these procedures in order to model the Western Cape agricultural sector. The characteristics of the Western Cape agricultural sector and in particular the production side thereof were taken mainly from the 1988 South African Agricultural Census Report (CSS, 1993), which provides the most recent comprehensive data on the subject. These characteristics served as the basis for the model described here.

The construction of the model was done in three distinct phases: first the basic model with costs and fixed prices only was assembled; second, risk was included by using the mean absolute deviation method (MOTAD); and third, variable product and input prices were modelled by using stepped demand functions. Each of these three stages is described in detail in earlier publications (Van Zyl et al, 1992; Van Zyl, 1995; Vink et al, 1997 ) and is not repeated here. The base year for the modelling exercise is 1988 , the most recent period for which a comprehensive data set is available.

Following from the above, the model consists of three distinct sections, namely the supply side depicting farm production and raw material imports which is characterized by the supply equations and the risk section, and the demand for the raw products, depicted by the set of demand equations. Transport activities link the supply and demand sections of the model together: each of the ten resource regions or two import 'harbours' can supply any of the three consumption points (the Western Cape region as a whole, and the two export 'harbours', Cape Town and Beaufort West). Supply and demand for each region are treated as if it is coming from a point or one specific locality, rather than from all over a region. This is done to make the treatment of transport costs between and within resource regions easier. Consumption and production points were subsequently developed to facilitate this. This is in line with the assumption that production practices, yields, risk and prices are the same within regions. The model thus has the following sections:

supply: $\quad$ production activities for 20 different commodities in each of the 10 resource regions; and import activities of some of the most important commodities (livestock products and winter grains) through any of the two entry points (Cape Town and Beaufort West);

linking activities: transport of commodities from any of the 12 supply points (two entry points and 10 regional supply points) to the 3 demand areas, i.e. the consumption point for the Western Cape as a whole, and the two exit points (Cape Town and Beaufort West);

demand: $\quad$ stepped demand schedules for each of the 20 commodities for its major uses (animal/human consumption within the Western Cape, the rest of South Africa or exports), each consisting often steps; and

risk: incorporation of production risk (six years of risk data).

The model was structured in such a way as to allow for the easy measurement of producer, consumer and total welfare. The objective function of the model maximizes total welfare (for a more detailed description of the model, see Vink et al, 1997). The number of activities, risk years and steps in the demand schedules are considered to be enough to allow for the desired degree of sensitivity when simulating policy changes. 
The data requirements are quite formidable as the data are not available in exactly the required format, and several sources had to be used for the collection. The data used for this analysis come from the 1988 Census Report describing agriculture in the Western Cape, the COMBUD publications of the Department of Agricultural Development, unpublished reports of the Department of Transport and SPOORNET, and data obtained from the Central Statistical Services (CSS) and from a number of agricultural marketing boards. As the most recent comprehensive data set was available for the 1988 production year, and given that 1988 was considered to be fairly 'normal', this year was chosen for setting up the model. All price and quantity data refer to this year.

For the construction of the model, data requirements are as follows: (i) production, area/number and yield data for the 20 selected commodities in each of the 10 resource regions; (ii) production costs for each of the commodities in each of the 10 resource areas; ${ }^{1}$ (iii) c.i.f. prices for each of the commodity imports; (iv) net export prices of commodities which are exported; (v) base prices and quantities of commodity consumption (for each of its major uses) in the Western Cape and the rest of South Africa in order to determine the step-wise demand schedules for each region; (vi) transport costs from every supply point to the consumption (demand) points; and (vii) risk data consisting of prices and yields of each commodity in each of the regions for the six year period 1983-1988.

\section{MODEL VALIDATION}

The testing of the model was performed by imposing all of the relevant policies which were current in 1988, specifically the marketing and pricing regime for each product, credit policy and other on-farm policies, in order to see how well it simulates the current (1988) situation. The better the current situation is represented by the model, the more reliable the model. The values generated by the model correspond fairly well with the actual values for the Western Cape as a whole (this is not necessarily true for each of the 10 sub-regions). ${ }^{2}$ If a deviation of 15 per cent is deemed acceptable for the model as a general rule of thumb (as suggested by Hazell and Norton, 1986), all the generated production quantities for the Western Cape as a whole are within this limit. A percentage absolute deviation of 6.94 per cent across all commodities for the Western Cape (as a whole) is obtained, which is adequate (and even good) for this type of model (see Table 1). The model can thus be accepted as being relatively accurate and can be used for simulating the effects of policy changes with some degree of confidence.

\footnotetext{
${ }^{1}$ Ideally, several enterprise budgets are needed for each commodity to model different points on the production function which can capture some of the farmers' reaction to changes in prices. This was not possible in this application as it would have required too many additional assumptions.

${ }^{2}$ In some of the sub-regions where very small amounts of a specific commodity are produced, the model predicts a relatively large deviation (increase or decrease) of up to 75 per cent of the actual production, but in absolute terms these variations are small and insignificant. Where a specific commodity is important in a region, the model predicts both the relative and absolute production levels fairly accurately.
} 


\section{RESULTS}

The results obtained with the different policy simulations are often a function of the set of assumptions that underpins the analysis. Therefore, explicitly stating some of the most important assumptions which impact on the subsequent results is necessary. Also, the direction of change is often much more important than the actual magnitude of the results obtained. For this reason less emphasis should be placed on the actual results than on the direction of change, while the assumptions which underpin the analysis (many of which are often only implicit) should be considered together with the analysis of the results.

Two policy scenarios were modelled to illustrate the effects of marketing policy changes on production, price and welfare of the major groups involved in the analysis: (i) free market system with no statutory price fixing or other controls with respect to domestic marketing arrangements of the commodities, and no imports of the commodities (or substitutes) are allowed; and (ii) free market system with respect to the domestic marketing arrangements of the selected commodities, as well as abolishment of all controls on imports.

Both these scenarios refer to a situation where the fixed-price single-channel marketing systems for winter grains and the floor price schemes for red meat, eggs and diary products (which were in place in 1988) are abolished and domestic market clearing prices are established through the interaction of supply and demand in a freer market economy (the pool price schemes for exports of citrus, deciduous fruit, wool and mohair are maintained) (see, for example, Meyer and Van Zyl, 1992, for a similar exercise). This situation allows for the establishment of different prices for each commodity in the Western Cape region and the rest of South Africa (e.g. with respect to wheat) for each of its uses, depending on the supply, demand and transport situation. ${ }^{3}$

The selected key variables, which are monitored to determine the effects of policy changes, include areas under production, employment, prices and welfare values. The values of these variables for the base scenario are used as basis for comparison in each case. The base values were derived by imposing all the relevant current (1988) policies, and then maximizing total welfare (with specific restrictions in place to model the current situations more realistically). Important is that all other variables, for example transport costs, exchange rates, international prices and interest rates, stay the same for each scenario. ${ }^{4}$

\footnotetext{
${ }^{3}$ An important consideration (and limitation of the analysis) is that it is assumed that market liberalization will not affect agricultural input prices (credit and labour excluded). It can be argued that it should also be taken into account (the structure of the model allows for easy incorporation). However, for this specific application, it was assumed that the monopolistic structure of competition between agricultural input suppliers will not allow for significant benefits in this respect (see, for example, Van Zyl and Groenewald, 1988).

${ }^{4}$ This is restrictive, but allows for evaluation of the effects of the specific scenario in relative isolation.
} 
Table 1. Comparison of modelled changes in the marketing system with base values.

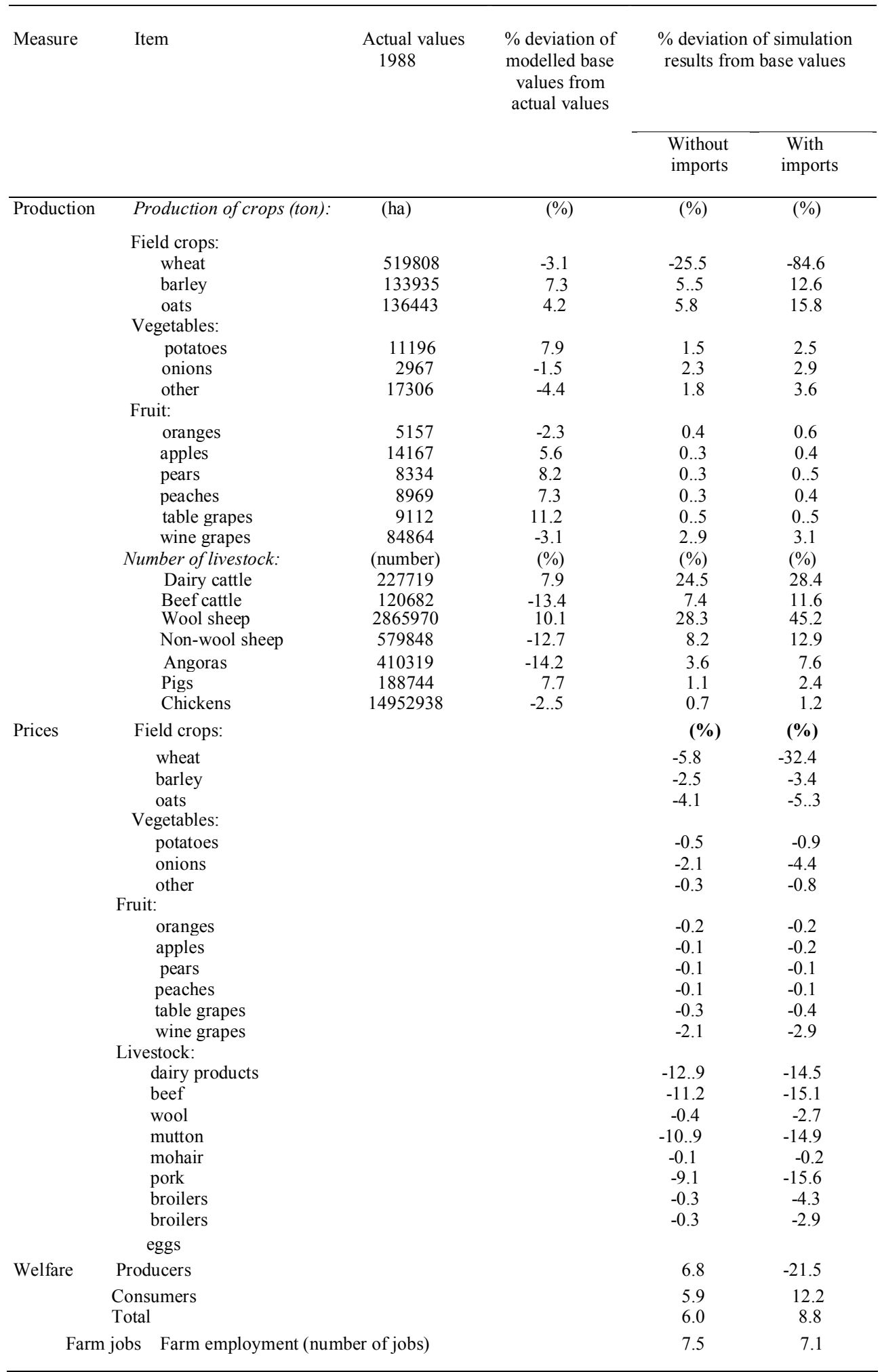




\subsection{Domestic Market Liberalization}

Table 1 shows that when domestic markets become freer and no imports are allowed, the production of commodities with marketing systems heavily regulated by statutory controls will be influenced most. In particular, production of wheat and other winter grains, and numbers of cattle and sheep are affected most.

Liberalization of grain markets, specifically wheat, is the key to explaining the changes in production. Abolishment of the single channel fixed price scheme for wheat causes the price of wheat to decrease by nearly 6 per cent. This causes a decline in wheat production of more than 25 per cent. The land freed up in this way is partly used for the increased production of other crops, specifically barley and oats. However, by far the largest portion is used for increasing livestock production, in particular in the production of dairy products and wool. Most of the other production changes are insignificant.

The freer market scenario negatively impacts on the producer prices of wheat, as well as the other two winter grains, while the price changes in other crops that were not influenced by statutory marketing arrangements (or to a lesser extent), are largely insignificant. The latter is not true for prices of controlled livestock products - prices of dairy products, beef, mutton and pork decline significantly. ${ }^{5}$

These tendencies cause the producer surplus to increase relative to that of the base scenario. On the other hand, consumers benefit from the lower prices with the result that the consumer surplus is nearly 6 per cent higher than in the case of the base scenario. The net effect is that the total surplus is also higher than in the base scenario.

This scenario clearly demonstrates how domestic marketing policies of specifically winter grains, dairy products and red meat have distorted production patterns in the Western Cape and how this has resulted in a social cost to the region and the country. The magnitude of this social cost is the opportunity cost of following other strategies, in other words the decrease in total welfare resulting from sub-optimal policy environments. Employment in agriculture is 7.5 per cent higher than in the base scenario.

\subsection{Trade liberalization}

When the marketing systems of the controlled commodities discussed above are liberalized, and import controls are abolished (with the assumption of a zero tariff level), the results are similar to these described above, but they are much more accentuated.

Production changes are again driven by changes in the wheat scenario. Because of the sharp decline in wheat prices (of nearly 33 per cent) to import parity levels, most of the wheat requirements of the region are imported, with the result that wheat production declines a staggering 85 per cent. This large chunk of land freed up in the process, goes partly towards the expansion of oats and barley production, but is again largely used for increased livestock production. In particular, the production of export products, like wool and mohair (and mutton as a by-product), gets a major boost - these products do not have the same limitations of a finite and often limited domestic market (both within the region and elsewhere in South Africa).

The above process goes hand in hand with decreases in prices of all commodities, although changes for all export-oriented commodities (both fruit and livestock products) are insignificant. Particularly negatively affected are prices of dairy products and red

\footnotetext{
5 As expected, there is a direct correlation between marketing control and production changes. Those commodities with the most intervention and control in their marketing regimes, and thus also deviation from market-clearing equilibria, show the largest changes.
} 
meat, with declines of more than 10 per cent. However, livestock production mainly on planted pastures still seems to be a better option than wheat production due to the relatively greater drop in wheat prices to import parity levels.

These processes cause producer welfare to decrease significantly by more than 20 per cent relative to the base scenario. On the other hand, consumer welfare increases by more than 12 per cent. In spite of the lower producer surplus, the increase in consumer welfare is the major factor in an increase of nearly 9 per cent in total welfare relative to the base scenario. This scenario clearly demonstrates how the marketing policies and specifically the trade policy of not allowing free trade cause a welfare transfer from consumers to producers, and resulted in a social cost to the economy as a whole (see section above). The marketing and trade policies followed clearly benefited producers and imposed a cost on consumers and the society as a whole.

The employment level in Western Cape agriculture is 7.1 per cent more than in the base scenario, which is marginally lower than when imports are not allowed. Importation of agricultural commodities thus results in the loss of some employment opportunities, albeit nearly insignificant in magnitude.

\subsection{Summary}

The results in Table 1 show that market and trade liberalization have major impacts on the structure of Western Cape agriculture. These impacts are, however, targeted on the grain and livestock sub-sectors, with only marginal and mostly insignificant and negligible effects on horticultural products, both vegetables and fruit. This is directly related to the degree of statutory control and intervention associated with the marketing process of these commodities - where intervention is severe, as in the case of grain and livestock (which are also related to each other because they are dependant on each other), the changes are relatively large and significant; where marketing is relatively free, as in the case of vegetables and fruit, changes are relatively small and insignificant.

\section{CONCLUSIONS}

The conclusions which are drawn from this analysis, subject to the numerous assumptions made, are that market reforms leading to increased market liberalization and in particular the lifting of controls on wheat imports - will have major impacts on the grain and livestock sub-sectors, while not influencing fruit and vegetable production much. The major results with some policy implications are that: (i) the grain and livestock sub-sectors are influenced by the simulated policy changes, while the horticultural industry, which seems to be pretty efficient and competitive, is not affected to any significant extent; and (ii) full market liberalization with no import tariffs will impact extremely negatively on grain farm profitability.

These conclusions are directly related to the many assumptions employed and shortcomings of the modelling approach followed. All of these limit the use of the model as it is, but does not invalidate the results given these specific assumptions. ${ }^{6}$ However, some of these assumptions which have major implications on the specific outcomes are

\footnotetext{
${ }^{6}$ Virtually all of these limitations/assumptions can be addressed by incorporating more scenarios and enlarging the model. However, to do this requires even more assumptions (often based only on subjective intuition) which require separate studies on their own just to validate or justify. There is little point in doing it here as this is not the objective of this analysis. Some of these scenarios, however, have been addressed in related work (see Vink et al, 1997).
} 
clearly unrealistic, for example the assumption of a zero tariff level on the imports of wheat. Nonetheless, it gives a feel for the magnitude, and more important the direction, of changes that can be expected in different scenarios. In this respect, this study often raises more questions than answers, but serves as a base for further analysis.

\section{REFERENCES}

CSS (1993). 1988 South African Agriculture Census Report. Report No. 11-02-02. Pretoria: Central Statistical Services.

Hazell, P. B. R. and Norton, R. D. (1986). Mathematical Programming for Economic Analysis in Agriculture. New York: Macmillan Publishing Company.

Kassier, W. E. and Groenewald, J. A. (1992). 'Agriculture: an overview'. In Schrire, R. (ed.) Wealth or Poverty? Critical choices for South Africa. Cape Town: Oxford University Press.

Kirsten, J. F. and Van Zyl, J. (1996). The contemporary agricultural policy environment: undoing the legacy of the past'. In Van Zyl, J, Kirsten, J. F. and Binswanger, H. P. (eds) Agricultural Land Reform in South Africa: Policies, Markets and Mechanisms. Cape Town: Oxford University Press.

Meyer, N. G. and Van Zyl, J. (1992). 'Comparative advantages in Development Region G: an application of a sectoral linear programming model', Agrekon, 31(4), 183-197. RSA (1984).

White Paper on Agricultural Policy. Pretoria: Government Printer.

Thirtle, C, Sartorius Von Bach, H. J. and Van Zyl, J. (1993). 'Total factor productivity in south African agriculture, 1947-1991', Development Southern Africa, 10, 301-318.

Van Zyl, J. (1995). Modelling the Western Cape agricultural sector. Unpublished Report, Department of Agricultural Economics, Extension and Rural Development, University of Pretoria.

Van Zyl, J. and Groenewald, J. A. (1988). 'Effects of protection on South African commercial agriculture', Journal of Agricultural Economics, 39(3), 387-401.

Van Zyl, J, Vink, N. and Fenyes, T. I. (1992). 'Effects of a farmer support programme and changes in marketing policies on maize production in South Africa', Journal of Agricultural Economics, 43(3), 466-476.

Vink, N. (1993). 'Entrepreneurs and the political economy of reform in South African agriculture', Agrekon, 32(4), 153-166.

Vink, N, Van Zyl, J, Van Seventer, D. and Eckert, J. B. (1977). 'The macroeconomics of rural livelihood creation in the Western Cape province: Macro effects'. In Lipton, M, De Klerk, M. and Lipton, M. (eds) Land, Labour and Livelihoods in Rural South Africa-Volume 1: Western Cape. Durban: Indicator Press, pp. 51-70.

World Bank (1994). South African Agriculture: Structure, Performance and Options for the Future. Washington DC: World Bank, Southern Africa Department. 